\title{
Early Warning Mechanism of College Students' Group Events
}

\author{
QIU Jia-cun \\ Guangdong College of Business and Technology, Zhaoqing, China
}

\begin{abstract}
According to the relevant data, many students want to participate in the group events subconsciously, which is a wake-up call for educators in universities. Based on the concept of harmony, we ought to consider ways to solve the college student group incidents fundamentally. When the campus is full of internal factors of disharmony, we must reconcile this atmosphere to ease the contradiction. It is requested that the school personnel should find a solution to solve problems emerging in the development to contribute to a harmonious society construction. Colleges and universities must set up the early warning mechanism of College Students' group events, which is of great significance in maintaining a steady development and one of the innovations of management measures for colleges and universities to cope with the development in the new era.
\end{abstract}

Keywords: college students, group events, early warning mechanism

\section{Introduction}

College students' group events include collective strike, strike meal, etc. This is a petition, that is, a group of college students gathering together in order to satisfy some purpose of equality. They are special events which will bring about inevitable damage to the society as harmonious stability in the university, from a certain extent, indicating the degree of stability of the society. College students involved in the group events express their potential will clearly, which is a phenomenon to be thought about. If some things can be prevented, it can also be solved. A long significance early warning mechanism of college students' group events will enable a long period of stability in the universities and the whole society.

\section{Investigation of the Current Status of Group Events Early Warning Mechanism}

According to the survey among some relevant management persons, there is a high possibility for college students to participate in group events. Their potential consciousness is obvious. Unfortunately, early warning system is far from being completed, and there are not any preventable countermeasures about college students' group events.

College students have strong will to participate in community events, which means the high possibility of group events. Some investigation in view of this phenomenon shows that many students will turn up in the campus if there is a group event, and they are very willing to participate in any kind of group event (WU, 2013). This also highlights how strong subconsciousness students have to take part in group events. Therefore, we can say that group events of college students have a certain mass foundation which agrees with the result of the

QIU Jia-cun, teaching assistant, MBA, School of Foreign Language, Guangdong College of Business and Technology. 
correlative research carried by the Ministry of Education. The local government and schools should pay much attention to this kind of consciousness of college students actively participating in group events. We cannot ignore the potential impact of group events. In psychology, "positive or negative attitude are somehow affected by the beliefs, emotions and responses" (XIE, 2008, p. 101). The main source comes from individual experience, which can be said to be able to be guided and predicted. Based on their own experience, college students agree on group events, which can be regarded as a support, and participate in this activity. If some people with impure motives stir up and instigate, a little thing can produce the butterfly effect. The occurrence of group events, even all the events in malignant, will cause social panic. Structure of group affairs includes the basic core layer, backbone layer, maintenance layer, on-lookers layer, and slow flow layer. The former two are the dominant figure in the event of a transaction, which have a decisive role to plan construction. Although the other three are not dominant, they also have a small effect on the scale of the expansion and impact of an event. They will also be the main roles to make event more complicated, just like catalysts. These students stepped in after the event began, promoting the development of this event.

Therefore, we must face up to group events of the college students and set up the early warning mechanism. The majority of managers are to receive professional training about the early warning mechanism of China's related college events. Thus the parties themselves devote themselves to college events prevention, and the school management personnel have more and more professional knowledge and application ability. But in reality, because its loopholes of construction of related regulations and emergency plan appeared one after another, only a small number of schools can be up to the standard, preparing to establish a perfect emergency team of faculty. Some colleges pacify the emotions of the students to avoid the events, but they do not have a preparatory scheme and the corresponding list management system with specification, which is not effective in the prevention and control of college students' group events.

\section{Analysis of the Causes of College Students to Participate in Group Events}

College life is closely linked with the whole social life. Therefore, college students pay much attention to the problems generated within the society. Their understanding of the society tends to these social problems. Their social role will make them unconsciously put some of their personal views into these problems. Since their own lifestyles in middle school have changed and they receive complex information; what they get involved with is of every hue, which will produce great impacts on college students.

In the past, the development of college students' impulse of taking part in social activities is accompanied with the corresponding social background. Since China's reform and opening up, all aspects of the inevitable contradictions arise in the society, and these disharmonious factors can be seen everywhere through various media channels, young people of this era, especially the college students, will be affected by such environment if they are used so that group events are very likely to break out, bringing about great damage to the stability of current social structure.

The sound of the organization can avoid the mass movement effectively, therefore, "avoiding the decomposition of body structure is an effective measure for the prevention of the mass movement" (ZHANG, 2007, p. 182). It is the priority among priorities to manage well universities gathering domestic elite. By doing so can we prevent such kind of group events. 
With the number of college student increasing year after year, the school management task has intensified because the management contents become changeable and relationship with students also tends to be complex. This type of relationship includes educational regulations, service relationship, administrative relations, and the market equivalent relation. All these relations together make up the complexity of the management and the problem. For example, where are the jobs of such a big number of graduates?

How to deal with the problem of more and more poor students? What is the solution to the contradiction between the school more and more unified system and students pursuing diversification? How to make logistics facilities and management services not lag that behind? If the solutions to these problems are increasingly discontent, they will easily convert to students group incidents.

The relationship between teachers and students has also changed, from the teacher's dignity before to a the-same-level relationship, or even an employment relationship. The teacher's dignity is weakened little by little, which is why we can see a cold relationship between teachers and students. Without much communication between teachers and students, most students who do not have correct guidance from their teachers become confused about their future so that it is very easy for them to deviate from the track, and even take risk to attend group events.

College life is a period of change from students to social people, so they have got no related social experiences which will lead to irrational performance as well as naive thoughts, a passion though so that they will have a serious moral sentiment. Although college students are somehow knowledgable, they lack social experience; if the situation of some group event is not analyzed thoroughly and put down with some measure, they easily go extreme and become fling caution to the winds. If they cannot find an appeal in expressing fair, with the stimulation of some incentives, group event occurs.

\section{Countermeasure Construction of the Early Warning Mechanism to Group Events}

Before the group incidents, there must be a corresponding warning, which we should manage to find timely and take some effective prevention measures. There have been many related research for us to fellow, such as CHEN and ZHANG (2010), LI (2003), and YANG (2006). To sum up, countermeasures to deal with college student group events consists at least the two steps as bellowing:

(1) Establish smooth mechanism of students' lawsuit about their interests. Expression of interest means the students maintain their own interests, pursue legitimate rights, and participate in some form of expression of the social life. If student's interest expression and the right to appeal is seriously suffocated, there will be inevitably an accumulation of destructive potential, which can arise in an extreme way when stimulated by some occasional factor. Therefore, it is quite necessary to build such smooth lawsuit mechanism of students interests and to widen expression way. Only by doing so can we effectively suppress and avoid those college group events in time;

(2) Set up a group events early warning mechanism. College group events early warning mechanism is that when the cumulative structural incentives and structural tension lead to trigger factors, we are supposed to be effectively sensitive to symptoms and signs of trigger events so that we can get college group events killed in the bud. The college group events early warning mechanism generally include the following measures: (a) pay close attention to building channels of expression of college students' interest and emotional catharsis. 
With the rapid development of information technology, Internet has become more and more important way of public opinion and give vent to their feelings (DENG, 2009). For school managers, they should regulate those websites, forums which college students love to log in. What is more, they should understand their favorite tool of communication, tracking the focus of their concern and sense of topics and areas of interest, keep abreast of their thinking; (b) establish a full range of intelligence network so as to have timely an accurate knowledge of the existing contradictions and unstable factors. Persons who are responsible for functional departments include counselor, teacher, student cadre, the network moderator, bedroom monitor. Information network system should train their sensitivity to group events warning; and (c) construct a reporting system. Colleges and universities should set up the relevant departments to collect, analyse, and study public opinion of college students' group events. According to early discovery, early reporting, early control, and early settlement principle, we can control problems in the bud (ZHANG, 2014).

What we could do can be suggested as follows:

(1) Try hard to manage students well;

(2) Make information management transparent and let the students know the content;

(3) Pay as much as possible attention to what the students are demanding and try hard to solve their problems as soon as possible so as to meet their appeal;

(4) Pay more attention to students' psychological quality. It is necessary for universities to set up counseling and training offices so that we can have a clear cognition about them.

\section{Conclusion}

Since the whole Chinese society are in the stage of growth, we must learn to solve the problems which arise naturally during the development. Based on the concept of harmony, we ought to consider ways to solve the college student group incidents fundamentally. When the campus is full of internal factors of disharmony, we must reconcile this atmosphere to ease the contradiction. It is requested that the school personnel should find a solution to solve problems emerging in the development to contribute to a harmonious society construction. Colleges and universities must set up the early warning mechanism of college students' group events, which is of great significance in maintaining a steady development and one of the innovations of management measures for colleges and universities to cope with the development in the new era.

\section{References}

CHEN, Z., \& ZHANG, Z. T. (2010). On construction of prevention system of college students' group events. Study on Chinese Youth, 2(2), 98-100.

DENG, Y. (2009). Internet influence on college students' group events. Chongqing University of Postal and Television (Social Sciences Edition), 21(3), 18-20.

LI, Y. F. (2003). The Principle and method of characteristics and the prevention and handling of efficient group events. Journal of Fujian Medical University (Social Sciences Edition), 4(3), 20-23.

WU, Y. (2013). Ideological and political study on college students' group events (Ph.D. thesis, Nanjing University of Science and Technology, Nanjing).

XIE, H. J. (2008). Analysis and control of mass incidents. Beijing: Higher Education Press.

YANG, X. Q. (2006). Methods and reflections on college students' group events. Socialist Study, 10(5), 115-117.

ZHANG, J. H. (2014). Legal countermeasures on college students' group events (Ph.D. thesis, Jilin University, Jilin).

ZHANG, Y. H. (2007). The education system of public emergencies management. Guangzhou: Guangdong Higher Education Press. 